\title{
SEDIMENT DYNAMICS BEHAVIOR AND BEACH PROFILE TYPES BASED ON SEDIMENT PROPERTIES
}

\author{
Gozo Tsujimoto ${ }^{1}$, M. Tamai ${ }^{2}$, Y. Takano ${ }^{3}$ and R.Yamaguchi ${ }^{4}$
}

\begin{abstract}
Sand samples along the shorelines and in the rivers of Tottori Prefecture were assayed for chemical elements using energy dispersive X-ray spectrometer. Samples contained more than 60 wt. \% Si, Al, Ca, Fe, Na and $\mathrm{Mg}$ less than $10 \mathrm{wt}$ \%. It was found by EOF analysis that $\mathrm{Si}, \mathrm{Al}, \mathrm{Ca}$ and $\mathrm{Fe}$ were the significant chemical elements. The spatial variations of first mode of $\mathrm{Si}$ are related to sediment dynamic behavior. The transport regime is net accretion when the first mode value of $\mathrm{Si}$ is increasing, and net erosion when being decreasing.
\end{abstract}

Keywords: sediment transport; EOF; grain size distribution; energy dispersive $X$-ray spectrometry

\section{INTRODUCTION}

Since sandy beaches have been playing an important role in defending the land side area, the importance of coastal conservation has been increasing further. Therefore, field surveys, laboratory experiments and numerical simulations have been carried out to obtain knowledge on beach conservations. Based mainly on these results, beach nourishment and coastal structures have been widely applied. But the sediment management considering river basins has not been done sufficiently. One of the reasons is that it is extremely difficult to evaluate the amount of sediment supplied from rivers, and the mechanism of sediment transport after reaching the coastal areas also not yet been sufficiently made clear.

Field observations using fluorescent sands or colored sands have been carried out to investigate the sediment transport dynamics in the coastal area, but there are problems of selecting sand inputting site and taking out sand particles from the collected sediments. In addition, under the sea weather conditions where the dynamics of sediment transport become active, it will be difficult to carry the filed observation itself in coastal areas. Therefore, focusing on spatial history of the sediment characteristics, analysis of sediment dynamics has been carried out using the physical properties of sediments, the chemical elements and the mineral composition. Measurements of sediment grain size with a sieve or identification of mineral composition using a microscopic requires a great deal time of time and skilled labor. Also in order to shorten time, an expensive laser-type particle diameter measuring device and the X-ray linear chemical element analysis instrument are needed. Against this background, Tsujimoto et al. (2012) calculated the sediment particle size, roundness, sand color and mineral identification from the image obtained using a commercially available scanner, and studying the relationships between the direction of sediment transport and the geology of the river basin.

As a study focusing on chemical elements among sediment properties, Ishiga et al. (2010) investigated the geochemical composition of beach sand on the San'in Coast, indicating that $\mathrm{SiO}_{2}$ has a negative correlation with the sorting coefficient. Terashima et al. (2013) analyzed the sediment grain size and the chemical element concentration changes. For river sediments, the element concentration become high as the grain size decreases, but there is no tendency for $\mathrm{K}$ and $\mathrm{Ba}$. It is because that the feldspar of felsic rocks derived from felsic rocks is difficult to refine.

Further as research examples applying the chemical elements in the sediments to the issues of sediment transport, Kumagai et al. (1997) determine the source of sediment transport using the correlation between two samples based on the chemical element ratio. Nagai et al.(2004) are tracking their moving path using the composition ratio of element of the gravels in the offshore area. In addition, Ishii et al. (2011) conducted elemental analysis of bottom sediments at Kujukurihama Beach, and tried to estimate the direction of sediment transport based on the relationships between colored minerals and colorless minerals.

Kato et al, (2013) investigate the beach profiles with the chemical elements in the sediments obtained by X-ray fluorescence analysis method. Okada et al. (2013) classify the mud distribution on the chemical composition of the muds in Tokyo Bay, and estimate the distribution range of the silt component and the sand component supplied from main rivers in Tokyo bay.

\section{FIELD SURVEY}

\footnotetext{
${ }^{1}$ Kumamoto University, 2-39-1,Kuromaki,Chuoku, Kumamoto, Kumamoto, 860-8555, Japan

${ }^{2}$ Osaka Sangyo University 3-1-1,Nakagakiuchi,Daito, Osaka, 574-8530, Japan

${ }^{3}$ Kinki University,3-4-1, Kowakae, Higashiosaka, Osaka, 577-8502, Japan

${ }^{4}$ Student, Kumamoto University, 2-39-1,Kuromaki,Chuoku, Kumamoto, Kumamoto, 860-8555, Japan
} 


\section{Study site}

As shown in Figure 1, the field observation was conducted at the coastal area of Tottori prefecture on June 5 and 6, 2014. About 300 gram of sediments was collected near the shore line of 21 beaches and near the downstream of 21 rivers. The collected sediments ware stored at room temperature after washing. We also measured the latitude and longitude of the sampling point using GPS. Three rivers flowing into the coastal area, the Hino-gawa River, the Tenjin-gawa River and the Sendai-gawa River, have larger basin areas and the flow rates than other rivers.

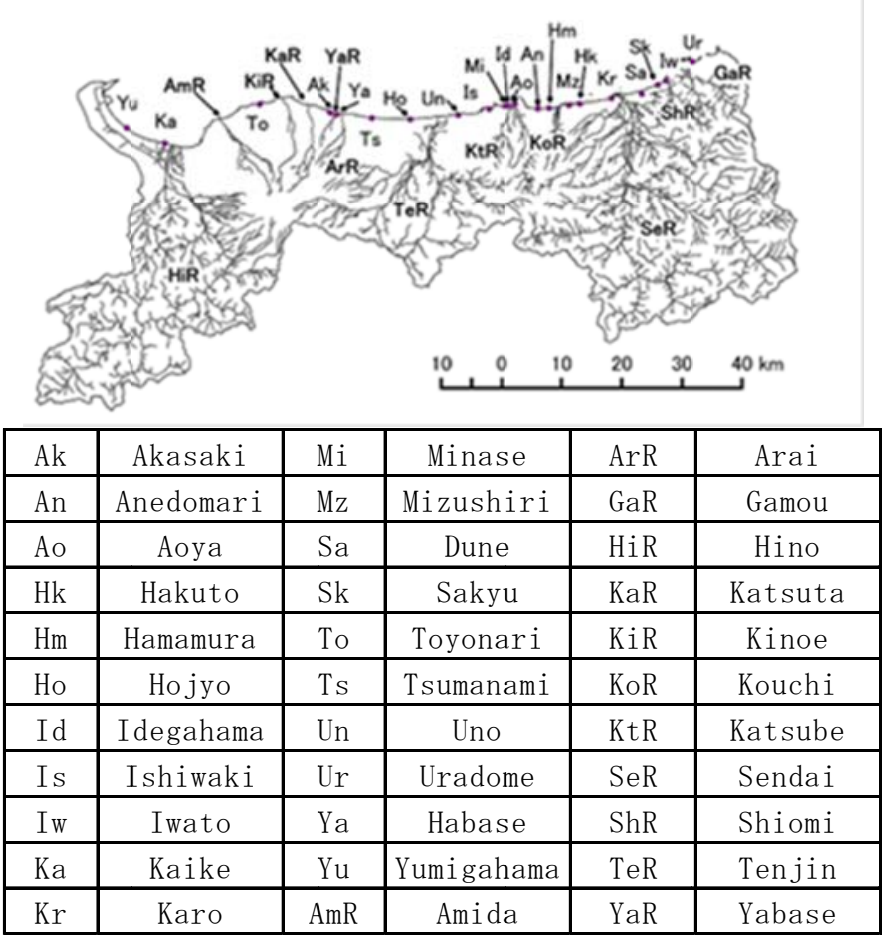

Figure 1 Observation sites.

\section{Geological Characteristics}

In order to investigate the relationship between the sediments of the beaches and the geology of the basin river, the geology was analyzed using AIST's Japan seamless map, and the range of the river basin using Quantum GIS.

Figure 2 shows the classification results of 12 river basins. The Arai-gawa River, the Yabasei-River gawa River, the Katsuta-gawa River, the Kou-gawa River and the Amida-gawa River have the same basin flowing down Mt. Daisen and Non-alkaline Pyroclastic flow is large. Also the Katsube-gawa River which has its origin in the vicinity of the top of Mt. Daisen has non-alkaline mafic volcanic rocks including colored minerals with the Amida-gawa River and the Kou-gawa Rivers.

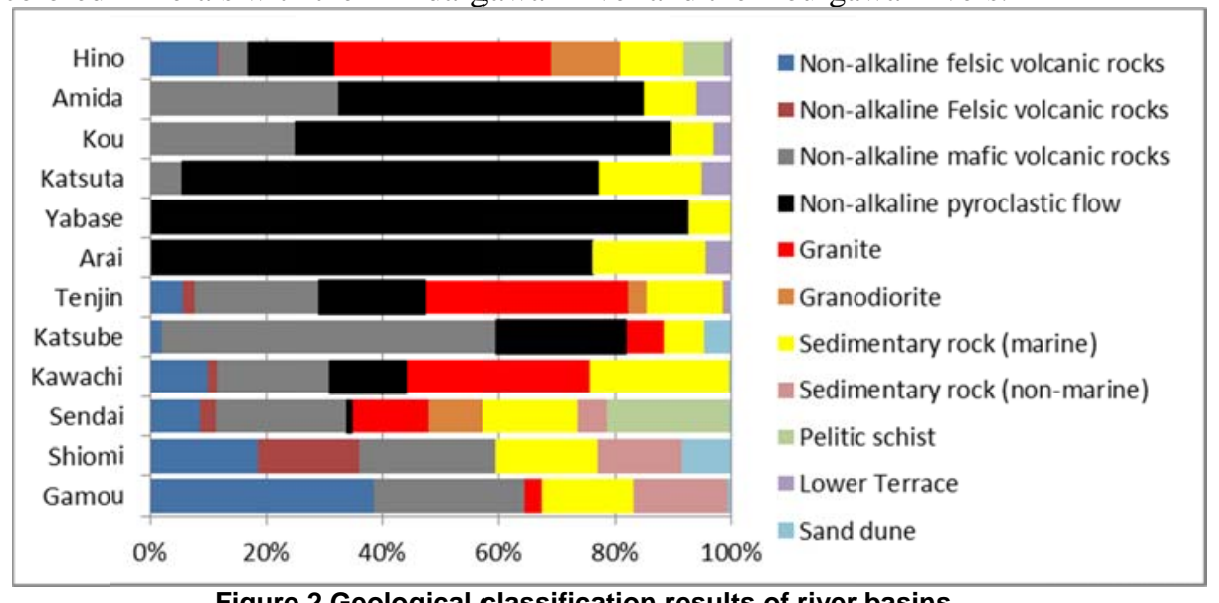

Figure 2 Geological classification results of river basins 
Figure 3 shows the results of a principal component analysis by the geology of river basins. The contribution ratios of the first component and the second component are $71.5 \%$ and $13.5 \%$, respectively. Depending on the geology, the area can be divided into two regions. One indicated that the geology has changed from hard iron volcanic rock to non-alkaline pyroclastic flow rocks. The other one represents the change from silicic rocks to granite. The Hino-gawa River, the Tenjin-gawa River and the Sendai gawa River with large flow rate and basin area are distributed on the red dotted line, so that the coasts of the Tottori coastal area have many quarts and feldspar minerals.

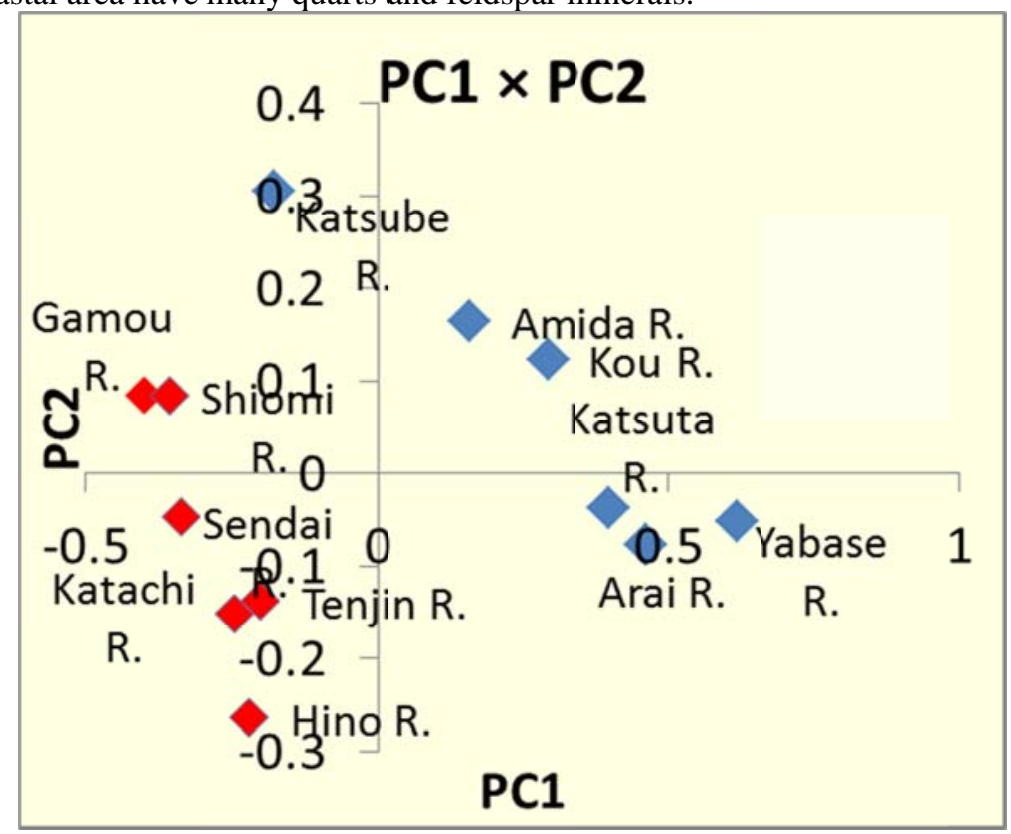

Figure 3 Geological classification results of river basins

\section{ANALYSIS OF SEDIMENT}

\section{Overview of Chemical Elements Analysis}

Sediment of $0.3 \mathrm{~mm}$ or less ware adhered to a circular sample plate with a diameter of $26 \mathrm{~mm}$ to which a carbon tape was attached on the entire surface. The Samples were coated with gold and palladium using a magnetron sputtering apparatus to prepare specimens. This specimen was placed in the specimen observation section of a scanning electron microscope (SEM), and an arcelerating voltage was set at $17 \mathrm{kV}$. A total of nine microscopic images (magnification: 30 times) were photographed. Since the image size is $1280 \times 960$ pixels, it is $3.2 \mathrm{~mm} \times 2.4 \mathrm{~mm}$. Figure 4 shows the image of sand particles taken by an electron microscope on the Mizushiri coast. The scale in the figure 5 is $500 \mu \mathrm{m}$.

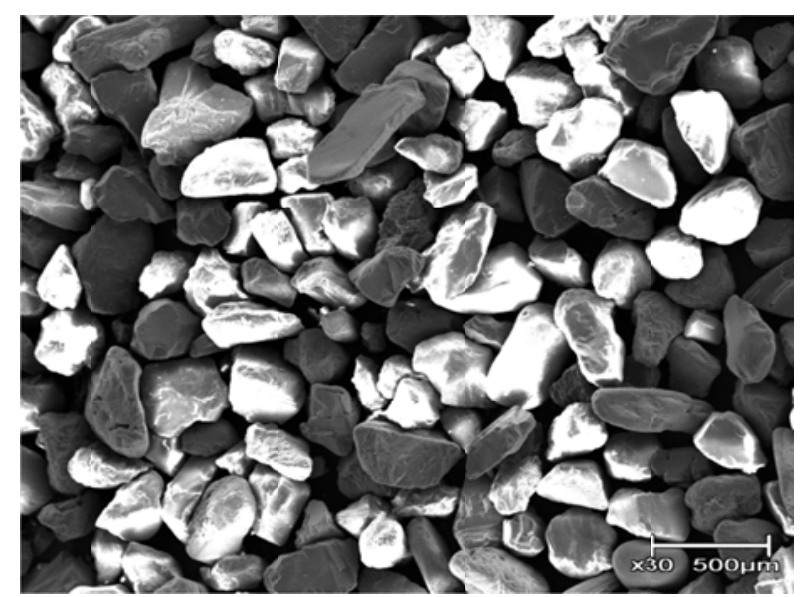

Figure 4 Image of sand particles on Mizushiri coast

The energy value and the intensity of the specific X- ray and its intensity in the sediments were measured using an energy dispersive $\mathrm{X}$ - ray spectroscope, and the elements constituting the sediment 
and its ratio were obtained. The sediment properties such as particle size, color and mineral composition were obtained using the method of Tsujimoto et al.(2012).

\section{Analysis Example}

Figure5 shows the result corresponding to Fig.4. The horizontal axis shows the elements corresponding to the energy value of the X-ray, and the vertical axis represents the number of elements corresponding to the intensity. On the Mizushiri coast, the ten kinds of elements are extracted and Si is the most abundant, which corresponds to the quartz of the minerals contained in the sediment.

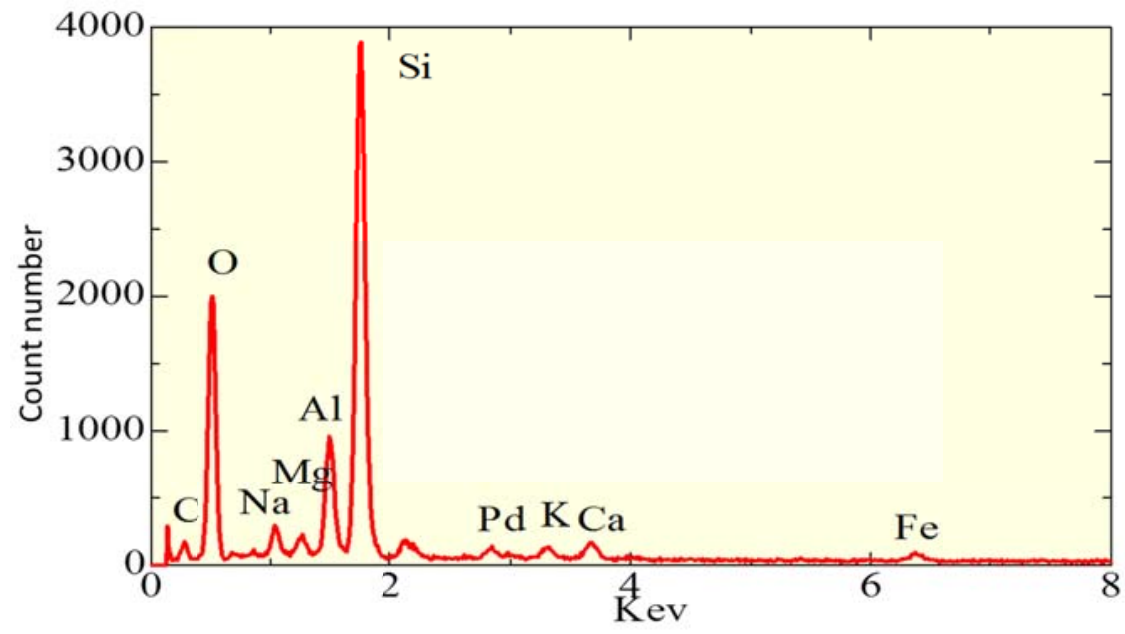

Element corresponding to the energy of the X-ray

Figure 5 Energy values of chemical elements and content number on Mizushiri coast

\section{Chemical Elements at Study Sites}

Figure 6 shows the percentage of chemical elements in each sampling sites. An average value of nine results of each site was used. 14 kinds of chemical elements are obtained; Si has 60 to $70 \%$ of the whole, Al, Ca and $\mathrm{Na} 10$ to 20\%, Mg and Fe about 10\%. They are the elements derived from quartz, feldspar, colored minerals (hornblende and the like). The Kaike coast and the Aoya coast have a higher proportion of Fe compared with other sites , the former being located at the mouth of the Hino-gawa River, which is the effect of producing sand iron from granite. The latter is due to the fact that it is located at the mouth of the Katsube-gawa River with non-alkaline mafic geology.

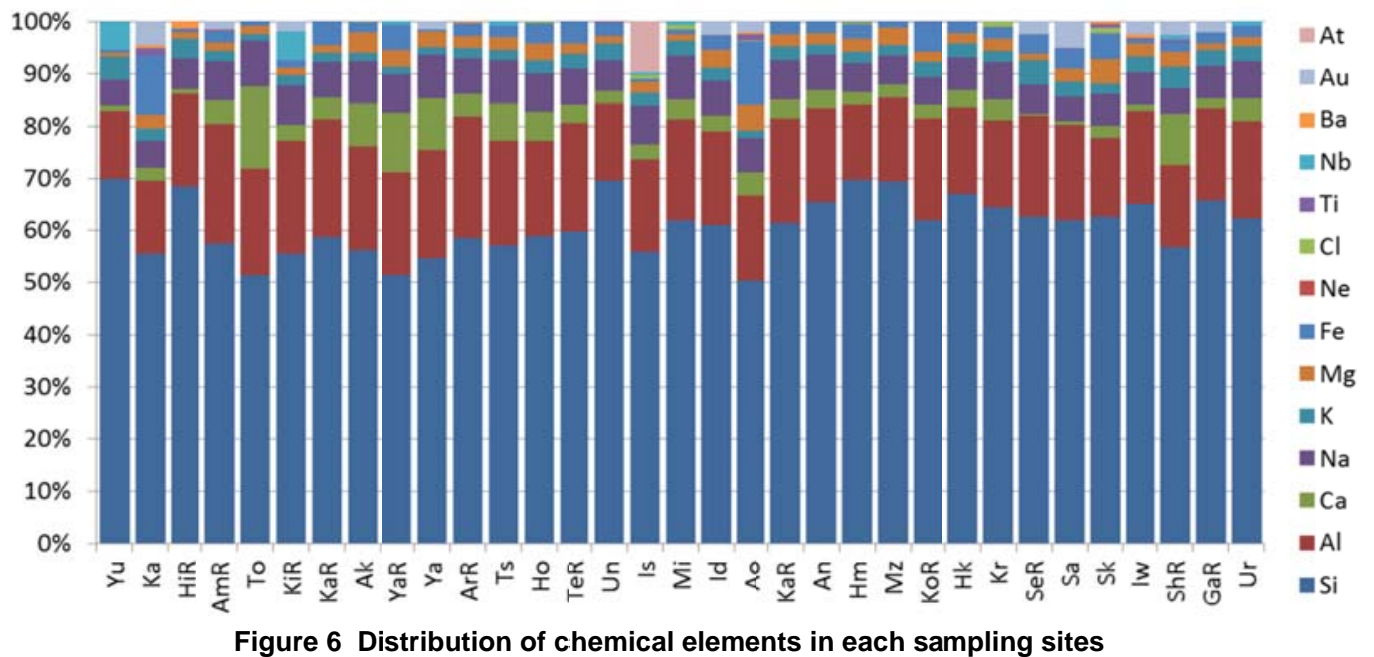

Figure 6 Distribution of chemical elements in each sampling sites

\section{DATA ANALYSIS}




\section{Analysis by EOF}

As an analysis example of chemical elements characteristic of the sediment, Okada et al. 9) use kmeans method, Kato et al. (2013) cluster analysis, and Kumagai et al. (1997) the correlation matrix method. On the other hand, Lee et al. (1991) has tried to analyze the sedimentation characteristics by applying the empirical eigenfunction method (hereinafter EOF ), but there is no application to chemical elements .

In this study the EOF was applied to analyze the ratio of the chemical element in the sediments. " $x$ " stands for kinds of element type, "i" for sampling site, $\mathrm{Gc}(\mathrm{i}, \mathrm{x})$ for content ratio of element " $\mathrm{x}$ " at sampling site " $\mathrm{i}$ ", $\overline{\mathrm{Gc}}(\mathrm{x})$ for the average of the element " $\mathrm{x}$ ". The deviation amount is represented as a liner summation of space and chemical element varying function:

$$
\nabla \mathrm{Gc}(\mathrm{i}, \mathrm{x})=\mathrm{Gc}(\mathrm{i}, \mathrm{x})-\overline{\mathrm{Gc}}(\mathrm{x})=\Sigma \mathrm{C}_{\mathrm{n}}(\mathrm{x}) \cdot \mathrm{E}_{\mathrm{n}}(\mathrm{i})
$$

where $C_{n}(x)$ and $E_{n}(i)$ are spatial orthogonal functions and corresponding chemical elements coefficient respectively.

(2) Analysis results

The first three chemical elements eigenfunction are shown in Fig.7.The contribution ratio of the first mode is $64 \%$, the second $17 \%$ and the third $8 \%$. The chemical elements with a large contribution ration are $\mathrm{Si}, \mathrm{Fe}, \mathrm{Al}$ and $\mathrm{Ca}$.

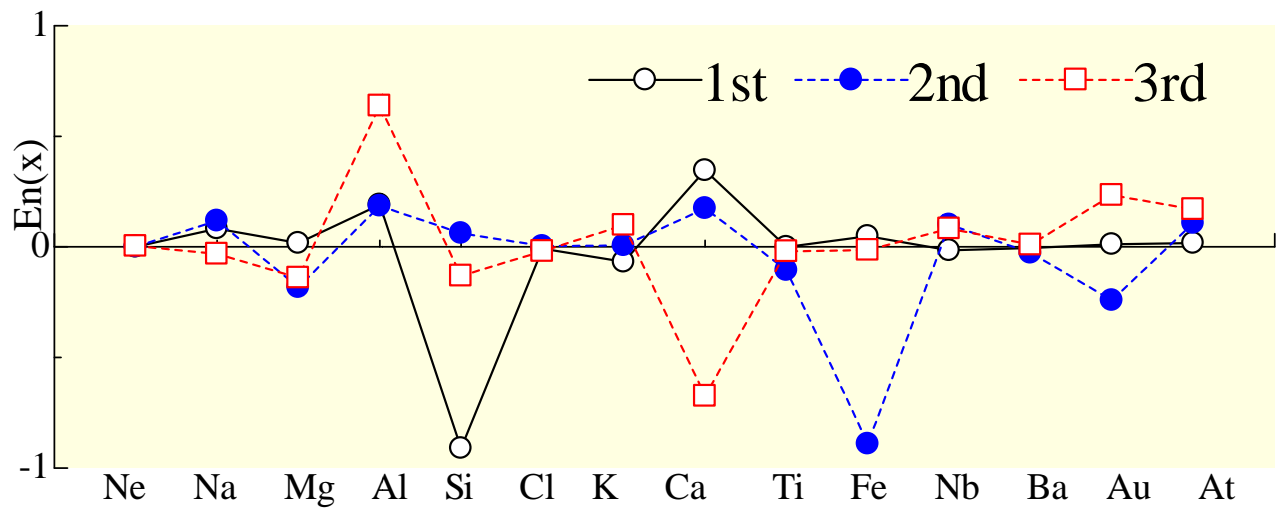

Figure 7 Variations of eigenfunction of chemical elements

Figure 8 shows the distribution of the spatial variation coefficient of a chemical element in the first mode. Si increases from the Toyonari coast to the Anegahama coast in the Tenjin-gawa River basin and Si decreases from the Hamamura coast to the Uradome coast in the Sendai-gawa River basin. Also Al and $\mathrm{Ca}$ are decreasing from the west to the east. Si has a negative correlation with $\mathrm{Al}$ and $\mathrm{Ca}$, which corresponds to the fact that feldspar decreases as quartz increases. Feldspar will be dissolved in Anorthite $\left(\mathrm{CaAl}_{2} \mathrm{Si}_{2} \mathrm{O}_{8}\right)$, Plagioclase $\left(\mathrm{NaAlSi}_{3} \mathrm{O}_{8}\right)$ and Potassium feldspar $\left(\mathrm{KAlSi}_{3 i} \mathrm{O}_{8}\right)$, and finally to Quartz $\left(\mathrm{SiO}_{2}\right)$ as the sediment were transported.

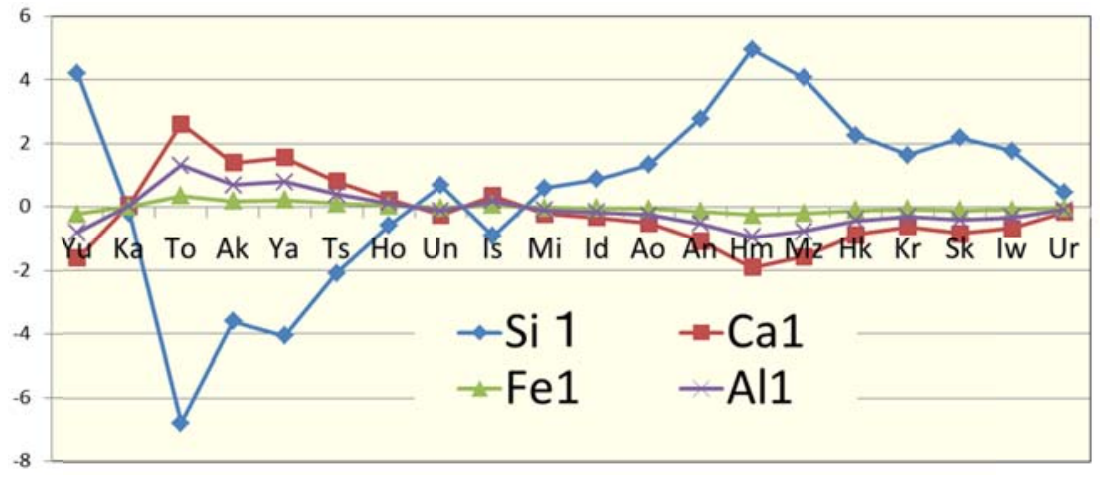

Figure 8 Spatial distribution of the first mode on chemical elements

Figure 9 shows the results of classifying quartz, feldspar and other minerals from samples using our method based on sediment color. The feldspar content decreases from the Toyonari coast to the 
Anegahama coast and the quartz content increases as a result. On the other hand, there is almost no feldspar from Anegahama coast to Uradome coast, quartz gradually decreased, which is corresponding to the variation of Si element in Fig.8

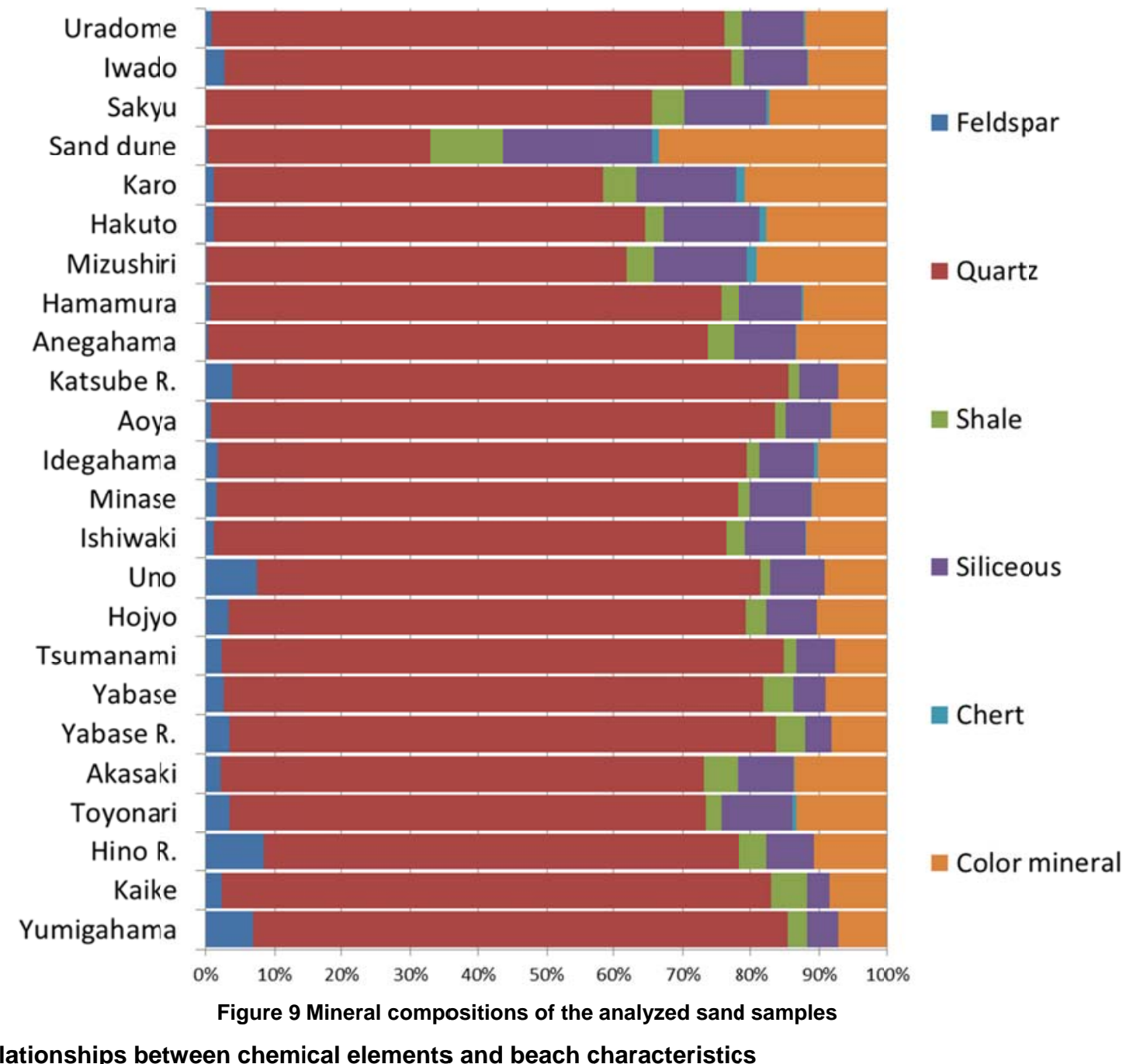

Relationships between chemical elements and beach characteristics

\section{Maturity of sand samples}

Sediments in the desert suffer severe wind erosion, so only quartz remains in the end. Mature desert sands are defined as follows. The quarts content in the sediments is high, there is a clear peak in the particle size distribution and the roundness is high. Figure 10 shows the relationship between roundness and $\mathrm{RM}$ which is the resistant index of maturity as the quartz content. $\mathrm{RM}=\mathrm{SiO}_{2} /\left(\mathrm{NaO}_{2}+\mathrm{CaO}+\mathrm{K}\right.$ ${ }_{2} \mathrm{O}+\mathrm{MgO}$ ). As the roundness of the sediment particles increases, the peak value of the particle size distribution becomes more pronounced, so the sediment maturity can be evaluatedl with the value of $\mathrm{RM}$ and roundness. The Tottori coastal areas can be classified into three regions, the blue color region is the coast of the Sendai-gawa River basin and red of the Tenjin-gawa River basin. The sediment maturity of the Sendai-gawa River basin is higher than that of the Tenjin-gawa River basin.

\section{Type of sediment transport}

MacLaren et al. (1985) use a function X(s) to classify the sediment transport type between adjacent beaches, where "s" is the grain size. The distribution of $\mathrm{X}(\mathrm{s})$ may be determined by $\mathrm{X}(\mathrm{s})=\mathrm{D}_{2}(\mathrm{~s}) / \mathrm{D}_{1}(\mathrm{~s})$. The particle size distributions on the upper side and the lower side are $D_{1}(s)$ and $D_{2}(s)$. Depending on the shape of $\mathrm{X}(\mathrm{s})$, the sediment dynamic behavior was classified into the following four types: A: Dynamic Equilibrium, B: Net Accretion, C: Net Erosion and D: Total Deposition.

Figure 11 shows the shape of $\mathrm{D}_{1}(\mathrm{~s})$ on the Hojyo coast on the upper side, $\mathrm{D}_{2}(\mathrm{~s})$ on the Uno coast on the lower side and the function X (s). The shapes of the three distributions are similar, but the mode of 
$\mathrm{X}$ is finer than modes of the D1 and D2. The grain size becomes finer from the upper side to the lower side. As a result, the sediment dynamic behavior is net accretion. On the other hand, the mode of $\mathrm{X}$ between the Mizushiri coast on the upstream side and the Hakuto coast on the lower side is coarser than D1 and D2 modes. As a result, the sediment dynamic behavior is Net erosion. Furthermore, the shape of D1 on the Sakyu coast on the upper side and the shape of D2 on Iwato coast on the lower side are almost similar, and the sediment dynamic behavior is Total deposition.
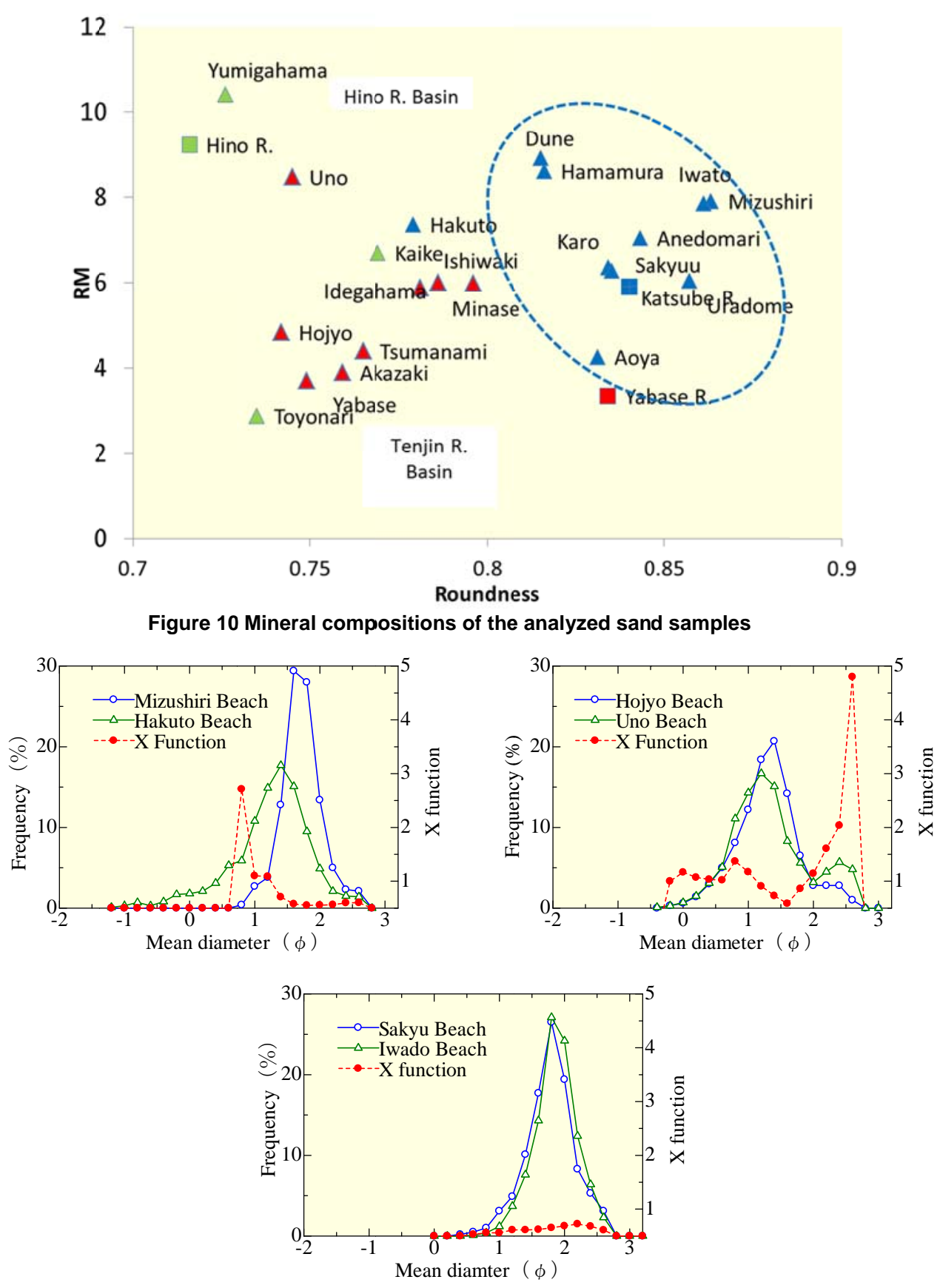

Figure 11 Shapes of X-distributions relative to the grain size distributions

The authors considered the roundness of the sediments in the model of MacLaren, calculating the sediment transport direction. In the Tenjin-gawa River basin, only case B (finer, better-sorted, and more negatively skewed) in the east direction was significant. Therefore the sediment dynamic behavior between Hojyo coast and Uno coast corresponds to type B. On the other hand, in the Sendaigawa River basin, both case B and case C (coarser, better-sorted, and more positively skewed) in the 
west direction are obtained. The sediment dynamic behavior between Mizushiri coast and Hakuto coast corresponds to type C. Furthermore, the sediment dynamic behavior between the Sakyu coast and the Iwato coast correspond to type A. As a factor causing the different sediment dynamic behavior, the sediment transport in the east-west direction due to seasonal variation is considered. Kawauchi et al. (2010) have conducted a total of four field surveys on the Tottori Sand Dune coast located on the east side of the Sendai rives in winter 2000 to 2005 and May 2009, and as a result, the same results as this research are obtained.

From Fig.8 and Fig.10, it can be said that the variation in Si element mode is positive ant the maturity is high on both the Hojo coast and the Uno coast classified as Type B, being negative and low on Mizushiri coast and Hakuto as Type C, and being none and moderate on the Sakyu coast and the Iwato coast as Type A.

\section{CONCLUSION}

Correspondence between the elements presumed from the geology of the river basin and the sampled sedimentary element is good. It was confirmed that $\mathrm{Si}$, Fe $\mathrm{Al}$ and $\mathrm{Ca}$ are important elements as chemical elements, and their variations correspond to changes in particle size and mineral composition. The variation of Si element mode and the sediment dynamic behaviors are related, the variation of $\mathrm{Si}$ element mode increases in the deposition type, and decreases in the case of the erosion type. These relationships focused on Si element are shown in Table 1.

\begin{tabular}{|c|c|c|}
\hline \multicolumn{3}{|c|}{ Table 1 Relationship between variation of Si and beach type } \\
\hline Correlation & RM & Beach Type \\
\hline Positive & High & Net Acceration \\
Negative & Low & Net Erosion \\
Non & Moderate & Total Diposition \\
\hline \multicolumn{3}{|c|}{ RM: Resistant Index of Maturity } \\
\hline
\end{tabular}

\section{ACKNOWLEDGMENTS}

In conducting this research, Mr. Tadahisa Sudoh (Former Industrial Technology Research Institute) gave advice on mineral analysis. In addition, a part of this research was conducted by Scientific Research Grant-in-Aid for Research (B) (Representative: Fumihiko Yamada graduate school Kumamoto University, issue number 22360199). I'd like to express my appreciation here.

\section{REFERENCES}

Tsujimoto Gozo , M. Tamai K. Uno and T. Kakinoki 2012. Study on Color Analysis of Sandy Bottom Quality and its Utilization, Civil Engineering Association Proceedings B2 (Coastal Engineering), Vol.68, pp.1456-1460 in Japanese.

Ishigaki Hiroaki, K. Kosaka and E. Sano 2010. Maturity from the viewpoint of pocket beach in the western part of the San'in Coast and element composition, Shimane University Global Environmental Studies Research Report, 29, pp. 21-31.

Terashima Shigeru, N. Imai, Y. Tachibana, K. Ikehara, H. Katayama, T. Okai, M.Ujiie, T. Ota, H. Kubota,2013 column: element concentration change associated with the particle size changes in the rivers and seabed sediments, geological research report, 59 Vol. 9 , No. 10 , pp . 439 - 459 , 2013 .

Yukihiro Kumagai and K. Mizumura,1997. Research on drift survey method using geochemical elements, Marine development paper collection, Vol . 13 , pp. 889 - 893, in Japanese .

Kenji Nagai, A. Nariya, T. Asano and T. Takagi,2004. Tracking the movement of nourishment materials using fluorescent X- ray analysis, paper on coastal engineering, vol.51, pp. 506-510, in Japanese.

Atsuko Ishii, H. Hagiya and K. Watanabe 2009. Estimation of sediment transport dynamics based on mineralogy and total composition of coastal sand - An example of Shonan Coast - Kujukurihama - , Ocean Development Papers, Vol. 25 , pp . 1107-1111, in Japanese . 
Shigeru Kato Shigeru, O. Tsubusemi, H. Koyama and S. Nakagaki 2013. Colored sand survey and sediment transport study of the X-ray fluorescence analysis in combination with estuarine, Japan Society of Civil Engineers Papers B2 (Coastal Engineering), Vol.69, No.2, pp.576-580,in Japanese .

Tatsuya Okada, A.Oribuchi and K.Furukawa 2013. Bottom quality distribution in Tokyo Bay based on chemical composition and particle size distribution, papers of the Society of Civil Engineers, B2 (Coastal Engineering), Vol.69 , No. 2 , pp. I_1121 - I_1125, in Japanese.

Makick, B. ML, E. Sano and H Ishiga 2011. Geochemical compostion of beach sand from Tottori Prefecture, Japan, Shimane University Earth Resources Environmental Studies report,30, pp.65 72.

Lee in-kook, I. Irie, N. Ono and K. Murakami 1999. On the method of surveying wide area drift sediment by bottom sediment analysis, Coastal Engineering paper, vol.46, pp. 656-660, 1999, in Japanese.

Tsujimoto Gozo and M. Tamai 2014. Influence of river to beach in Awaji Island by color-based mineral analysis , papers of JSCE B2 (Coastal Engineering), Vol. 70 , pp. 641-645, in Japanese.

Suwa Kenji, M. Hoshino and M. Osaki 2003. Diversity of Desert Sand, African Studies, Vol.63, pp. 17 - 26, in Japanese .

MacLaren, P. and D Bowles 1985.The effects of sediment transport on grain-size distributions, Journal of Sedimentary Petrology, Vol 55, No.4, pp 798-808.

Tsujimoto Gozo, M. Tamai and S.Nakaj 2013. Study on the direction of movement of drift sand by characteristic values of sandy bottom sediment obtained from images, papers of JSCE papers B2 (Coastal Engineering), Vol.69, pp.1456-1460, in Japanese .

Kawauchi Hayato and Y. Kodama 2010. East-West change of grain size composition found in sandy sediments along the Tottori Sand Dunes, Regional Studies, Volume 6, No. 3, pp. 325 -326 . 